\title{
Spermatid injection fertilizes ethics debate
}

Paris. A fierce debate has reopened in France over the ethics of creating children by directly injecting human eggs with individual spermatozoa - a technique known as intracytoplasmic sperm injection (ICSI).

The controversy follows the extension of the technique to the injection of spermatids, the round unflagellated precursor cells of spermatozoa that are normally only found in the testicles but also occur in the semen of many infertile men who lack spermatozoa - a condition known as azoospermia.

At the heart of the dispute is concern that the treatment is already being used on experimental human subjects without what critics consider to be either adequate prior animal studies or evidence that the condition is sufficiently serious to justify such studies being bypassed.

Earlier this year, spermatids from sterile males were injected into human eggs in an attempt to remedy azospermia in seven test couples. The first baby produced using the technique was born in June, and the second last week, at the American Hospital in Paris. No genetic or morphological abnormalities have been detected in either babies.

The results were reported in August in the New England Journal of Medicine by Jacques Testart, head of the Gamete Maturity and Fertilization Laboratory in Paris of INSERM, the national biomedical research organization, working in collaboration with Jan Tesarik, of the American Hospital in Paris, and Carmen Mendoza of the University of Granada in Spain.

Ironically, Testart is one of France's most outspoken critics of the ethical risks of medically assisted procreation. In 1982, he became one of the 'fathers' of France's first test-tube baby, Amandine. Four years later, however, he called for a moratorium on such research, in particular because of his concern that the techniques could be used for eugenic ends, and announced that he himself was giving up work on in vitro fertilization (IVF) - apart from its use to treat infertility (see Nature 385, 323; 1986).

Now Testart is under attack over what Axel Kahn, director of INSERM's genetics and molecular pathology research laboratory at the Cochin Institute of Molecular Genetics in Paris, calls "the biggest ethical problem since the development of medically assisted procreation".

In particular, Kahn claims that Testart's experiments - as indeed other human tests of ICSI - conflict with the 1947 Nuremberg code of medical ethics. This states that experiments on humans should be preceded by adequate animal experiments, and that any risks taken should correspond to the urgency of a given situation.

Kahn claims that ICSI is aimed at treating sterile couples who already have the alternative of using sperm from anonymous donors. He argues that while using gametes from the male partner might be considered preferable to those from an anonymous donor, the medical condition of such couples is not sufficiently urgent to justify the use of highly experimental techniques.

He also points out that the original ICSI technique was developed without any pre$\Sigma$ liminary experi$\stackrel{\vec{w}}{\bar{z}}$ ments on animals. Testart has replied IMAGE UNAVAILABLE $\sum_{\text {o }}^{>}$technique in rab-

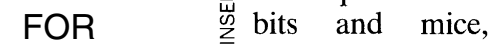
COPYRIGHT REASONS

Testart: claims that birth of healthy 홍 young which themselves were able to reproduce.
But Kahn claims risks are 'low or zero'. that the animals used were not appropriate models, as they were fertile and produced normal healthy sperm.

Speaking at the XV World Congress on Fertility and Sterility at Montpellier last week, Testart rebutted such criticisms. "What sort of discovery or scientific innovation can we expect which would allow us to act with complete certainty as to the results? None!" he said. "We're in a period - as often in medicine - where the choice is between doing nothing or doing something."

Testart also claims that the evolution of the spermatid into a spermatozoon does not appear to correspond to any modification necessary to embryonic development, but only to the acquisition of the properties needed for the transport of the male gamete and its fusion with the egg.

The risks involved, he has argued, can be "reasonably estimated" as "low or zero", and would in any case affect only the early viability of the zygote, not the fetus or child. Spermatids are genetically mature, he claims, adding that it is "difficult to imagine how their contribution to the embryonic genome could lead to abnormalities".

But critics such as Kahn argue that there are legitimate reasons for concern that ICSI — in particular using spermatids - might be dangerous, in particular because the use

\section{AZT combination trial shows positive results}

London. A trial studying the effects of the anti-AIDS drug AZT when given jointly with one of two antiretroviral drugs has shown that patients with HIV and AIDS receiving the combination therapy survived considerably longer than those receiving AZT alone. As a consequence, the trial, backed by three major pharmaceutical companies, has been stopped early.

The decision to release the preliminary results of the so-called Delta trial, which of cells selected at random avoids the competition between sperm that takes place in conventional IVF. Geneticists at last week's meeting in Montpellier also argued that sterility may result from serious chromosomal accidents, and that artificial means of overcoming such sterility may therefore risk producing seriously deformed children.

Indeed, the French national bioethics consultative committee last year advised that ICSI should be carried out only after comprehensive animal experiments have been done. But Testart says that animal experiments could delay therapeutic applications, while not providing any additional useful information.

It is too soon to know the real risks of ICSI. About 600 normal children have been born following conventional ICSI, using spermatozoa. But a group of Belgian and Dutch researchers reported last week, in a paper published in The Lancet (773, 346; $1995)$, that in a study of 15 embryos conceived using ICSI, five showed serious genetic abnormalities in sex chromosomes.

Yet Kahn argues that the outcome of the scientific debate is irrelevant. "Even if ICSI works, it doesn't change my analysis by one iota," he says. "For the first time since the Nuremberg code was drafted, we have embarked on human experiments aimed at creating humans without any great urgency for such experiments."

But Testart argues that the couples prefer the new techniques to using sperm from anonymous donors, and are willing to accept the risk, for example, that the male children born may themselves be sterile, arguing that the parents appreciate that treatments for sterility are likely to become available in their children's lifetime.

Ironically, during the debate over France's bioethics bills in 1993, Testart was among those who called for a total ban on pre-implantation diagnosis and selection of embryos. In line with many researchers and physicians, the National Assembly eventually decided that such techniques should be permitted in "exceptional cases", namely where parents risked bearing a child with a "particularly serious" genetic disorder.

Declan Butler

started in 1992 and involved more than 3,000 participants in Europe and Australia, was announced earlier this week at a conference in Copenhagen.

The preliminary results showed that 17 per cent of participants who took AZT alone and had not taken the drug before died during the trial, compared with 10 per cent of those who took AZT with didanosine (ddI) and 12 per cent of those who took it with zalcitabine (ddC). 